\title{
Indigenous identity: Summary and future directions
}

\author{
Bette Jacobs \\ Georgetown University, Washington, DC, USA \\ E-mail: bette.jacobs@georgetown.edu
}

\begin{abstract}
Indigenous people are distinct groups where a larger population grown up around their original place exerts political dominion over the original people. Statistical measures formulated as data are foundational to public decision making. In this journal issue on Indigenous identity, historic and contemporary circumstances reveal how measurement and lived experience translates into data. Examples represent global Indigenous diversity. Key themes examined are 1) operational definitions 2) why selecting what to measure and how to measure is relevant to Indigenous meaning as well as to serve with reasonable utility as subgroup data 3) invisibility as a common problem for Indigenous people consequent to insufficient measurement methods and political inaction 4) how to understand data comparison and 5) the ways in which political recognition and rights are embedded in measurement strategy. Identity rooted in a place shaped Indigenous culture just as evolutionary biology shaped Indigenous people's physical traits. Accordingly, Indigenous identity involves land claims, jurisdictional reach, and restitution. Agreements and tensions affect individuals. Therefore, Indigenous identity is individual and collective. Some governments recognize Indigenous communities with different legal instruments and engage Indigenous in varying degrees with a government to government approach. Other governments impose definitions and data frameworks from the state on to its Indigenous population. The UN Declaration supports Indigenous people self-determination across a range of domains but most particularly about inclusion and exclusion criteria for belonging to a group. There are different ways inclusion or membership is assessed by an Indigenous group, however, all use some measure to ascertain ancestry. Unique to this collection of papers, is the predominance of people who belong to Indigenous communities and those who have worked within our communities over time which we propose is the best step to achieve useful Indigenous data.
\end{abstract}

Keywords: Count, ways of counting, culturally appropriate/culturally responsive, data analysis, data ownership, decision-making, genetics, Indigenous Identity, Indigenous expertise, IGIHM (International Group on Indigenous Health Measurement), Indigenous professionals, jurisdiction, laws related to Indigenous identification, measurement, research methods/methodologic fit, resilience, self-determination, sovereignty, vulnerability

\section{Introduction}

The human condition for Indigenous people is sometimes described as marginal, minority, and vulnerable. Yet Indigenous people have a distinctly full human experience defined by a deep sense of belonging to a place from which our people were created. This is Indigenous identity. Interaction of distinctive people over millennia create biologic and cultural variation that bind groups together. Australian aboriginals, for example, are considered to be the longest lasting civilization in a particular area, having occupied their land for some 100,000 years. This definition of Indigeneity, can be summarized (as most phenomenon can be) in statistical terms. Qualitative data similarly provide other merits and limitations. As a political and legal construct, Indigeneity may be a relative concept. Yet identity is the core of human potential. These aspects and key issues associated with data on Indigenous people are introduced in this issue of JIOAS.

Since data analysis for diverse purposes commonly seeks to examine racial, ethnic and cultural variation among populations, it is imperative to improve understanding of Indigenous identity and, most particularly, to advance the premise that inclusion and data quality for Indigenous people are essential matters for data sets that collect racial, ethnic or cultural data.

Statistically, there are reasons to ascribe marginality, 
minority, and vulnerability to Indigenous people, particularly in settler states. Like all summary measures, data tell only part of the story. We argue that statistical methods are capable, indeed, responsible to include Indigenous people in datasets that describe groups of people and that all appropriate applications for assuring data quality and responsible use be employed when doing so. As original people occupying a place longer than written history, we are not marginal, minority, and vulnerable in exactly the same ways most people perceive these ideas but from a statistical data point of view, this may be correct. Other types of data limitations for Indigenous people must be changed to employ the rigor expected for all data sets. Too often, data on Indigenous people have not been good quality. Only through equitable expectations can data adequately guide decision-making. In this set of papers and synthesis, we provide examples where gaps, mistakes, or misunderstanding can be a result of lack of rigor as well as lack of political will. Underlying the varied communities featured is the remarkable phenomenon of resilience among Indigenous people and our flourishing cultures. Understanding resilience in statistical terms also contributes to the common good.

\section{Background}

Identity issues are central to any data set and, most particularly, when applied statistics are used for description and decision-making. Definitions about identification for Indigenous people come with common and distinctive concerns about counting, data analysis, and conclusions. The papers in this journal devote attention to a general sense of the range of concerns and how they are experienced by Indigenous people. Above all, the papers underscore how burdens for Indigenous people can be magnified by statistics that neglect or misrepresent native populations. Indigenous people also represent some of the most remarkable aspects of resilient identity. Findings that exclude or accept flawed data for Indigenous people diminish full understanding of the human condition and its rich, collective potential for understanding and for action. As the International Group on Indigenous Health Measures (IGIHM) we have spent more than a decade delving into the complexities involved with improved measurement. We are a multi-disciplinary group, many of us members of Indigenous communities, using mixed methods as appropriate to understand data about Indigenous people. In our respective places, we com- municate a lot about disparities, those measures that demonstrate how disproportionately Indigenous people achieve equality in education, health, economic, and justice. At our meeting in Vancouver in 2014, we established an identity sub-group within IGIHM to take up this fundamental focus. Selected papers on this topic were presented at the meeting of the 2018 meeting of the International Organization of Applied Statistics. With the special edition journal on Indigenous Identity there is the opportunity to integrate efforts of IOAS and IGIHM on a path of mutual productivity.

\section{Importance}

Statistical data seem the most unbiased form of representation possible. More than ever, data have become "evidence". Certainly, in most aspects of daily life, data about human differences increasingly inform ways of thinking and acting. Policies are designed and resources distributed by applying statistics to solve public concerns. Computer capabilities allow us to manage large amounts of data and examine enormous complexities. In the medical field, genomics relies on massive statistical correlations from genetic DNA to ascertain answers to questions as part of what is called "precision medicine". Accordingly, this is an ideal time to posit the importance of basic ways we characterize data and how to use statistics yielded from data collection. There are tremendous ways data advance knowledge and the ability to improve the human condition.

Anyone who works with numbers knows that precision from numbers come with certain qualifications. Identity has many elements. There are various ways to define, measure, include, exclude, and enumerate racial, ethnic and cultural identity. Operational definitions that specify these characteristics are essential to know and explain data as they are collected and interpreted. What is measured and how it will be measured is not only a function of instrumentation but one of focus and values about what is important. Therefore, counting is about numbers filtered through choices. Instrumentation varies tremendously, as anyone who deals with numbers appreciates. The selection of variables to be measured also is a critical point in time to consider inclusivity and diversity. Finally, while enumeration is generally the feature statistic, numerators are primarily understood in the context of denominators. For Indigenous people, denominators vary in quality as well. This is particularly essential to appreci- 
ate when dealing with the types of data that commonly translate into rates or ratios for reporting and comparison. Decision making is done with data or by default. All too often default happens in significant policy decisions because data are absent or little effort is made to look for data with relevant measures about Indigenous people. As Waldon [1] describes in this issue, establishing meaningful ethnicity classification standards and rules is a critical part of the solution to improve the health and well-being of Indigenous people.

\section{Indigenous identity}

Dealing with data about Indigenous people means dealing with country specific laws, treaties, colonial legacies, and between group and within group variation among tribes. Concepts of cultural belonging, self-determination, and sovereignty are also associated with identity. The UN Working Group on Indigenous Issues [2] emphasizes the intergenerational aspect of groups of peoples who identify themselves as communities or nations with long established, that is presettler or treaty claim, to particular territory. This definition of Indigenous identity embeds the idea of ancestral territory enduring for future generations. The UN, however, has limited jurisdiction and enforcement capabilities related to disputed territories for Indigenous people. Having a common forum has fostered strength of purpose and a forum for resolution models that recognize the rights outlined in UN declarations.

Identity as Indigenous has many expressions. Actionable definition arises from the political and legal meanings ascribed to human boundaries. Among multiple differentiating boundaries operating in Indigenous communities in Western settler countries, tribes and states have formal agreements defining Indigeneity. Presently, in order to be recognized by the countries of Canada, Australia, New Zealand and the United States, tribes must have written constitutions that specify their membership criteria [3]. Tribal membership criteria contain attributes that clearly state who is included and excluded for membership and may be changed as tribes deem appropriate as part of the legal right to self-determine this measure. Tribal definition of indigenous membership is recognized by these governments for all formal claims. Other countries, such as the situation Santos [4] describes in Brazil, impose definitions for Indigeneity in official statistics and while forward steps have been made, including efforts to meet international recommendations for measuring
Indigeneity, forward steps illuminate more specifically where gaps and questions could lead to improved measures and better probes.

Indigenous membership and human rights have been recognized by national and international bodies. Indigenous identity can be difficult in theory as well as law and policy. Sound data is key to formulating ways to define Indigeneity as appropriate to purpose. Importantly, it should be recognized that there is a growing number of Indigenous people credentialed in professions who can bring the rigor of science and essence of the lived experience to understanding statistics. The most important recommendation distilled over the experience of IGIHM has been training and inclusion of Indigenous people in bodies that design, deploy, interpret, and maintain how data are collected and used.

\section{Indigenous people data themes}

\subsection{Definitions}

There are different ways to define Indigenous identity. Formal claims and participation in tribal governance requires membership congruent with a tribal constitution. Membership is essential for legal action and certain benefits and rights. In some places and at certain times, tribal membership is notably fraught with disincentives and discrimination. In places where standards are established, tribes are given considerable authority to define their own membership criteria. Marori are the Indigenous people of New Zealand. Australia recognizes different tribes and nations of aboriginal descent as well as Torres Strait Islanders and their descendents whose numbers are greater on mainland Australia than on the Islands themselves. While tribal membership is generally the commonly understood term to specific Indigeneity, under certain constitutional circumstances other terms may be used to mean Indigenous membership. This is the case for Alaska Natives (AN) who identify with their tribal communities as "shareholders". ANs who identify as shareholders mean they are Indigenous members of one of twelve Alaska Native Regional corporations established in 1971. This is not the case in other places, illustrating the varied forms of organization and even terms Indigenous people have when referring to identification with their Indigenous community.

Self-identification is a different but conventional way to declare affinity with a racial or ethnic group. Self-identification remains a common method to mea- 
sure identity partly because it can be done efficiently in large scale data collection. There are various limitations accepted when using self-identification. As populations become more diverse due to mobility and mixed ancestry, people cannot be defined exclusively by where they live even though territory is a primary source of identity. This association with place and selfidentification is similar to how we understand identity as Irish or Jewish. Also, under different conditions there are incentives and disincentives for how one identifies ethnicity. Understanding how statistical data are defined and obtained explain such things as a surge in Indigenous identity in the US census without commensurate growth in birth rates and without identification of specific tribal affiliation. In certain circumstances, such as education or medical intake data done by interview, ethnic identity is not always even selfidentification but a judgement made by a person completing a data form. Tribal enrollment, on the other hand, has specific inclusion criteria to establish identity. Generally, criteria directly or indirectly reflect lineage that is biologic, social, and cultural. Partly this recognition arose from dominant governments using tools of blood quantum or named categories for full and mixed race. Because there are different standard ways of measuring, we agree that at least when practices, for example, rely on self-identification, that selfidentification can be the most reasonable definition to use. As Connolly et al. [5] and Griffiths et al. [6] write, whether or not self-identification is informative depends on the purpose of data collection.

The resilience of Indigenous people has been highly aligned with self-determined identity, a feature that resides within Indigenous communities and their traditions. The right to self-determine, perhaps more than any other single attribute, is an authority most championed by Indigenous peoples. Identity methods that have been externally imposed have generally caused disruption leading to dysfunction [1]. Recently, growing popularity for the commercial use of genetic testing for ancestry has introduced a new way to measure racial and ethnic identity. Although DNA ancestry measurement is data-based, at this point in time, it does not meet inclusion eligibility for any tribal membership criteria. These are many questions about the utility of such measures for the future. Instrumentation gives certain types of information and all data are qualified in some way. Human rights for Indigenous people strongly advocate for communities to make their own decisions about identity and belonging. Thus, actionable purposes rely on membership in a group rather than self-identification or externally created criteria.

\subsection{What to measure}

The selection of what to measure is a major data responsibility. A key purpose to measure identify is to learn about variation within and between groups of people. In diverse cohorts, this requires consideration of how to best represent phenomenon of interest. Procedures for formally including and deciding what to measure in official statistics is typically granted within existing Western forms of governance and reporting processes [6]. Exclusion or irregular inclusion in representation of data sets purported to describe national populations present problems to understand epidemiology or health data reports where comparisons and resource allocation typically use a reliable denominator $[1,7]$. Survey measurement using questionnaires may not assess culturally appropriate features. For example, health indicators that correlate with disease risk may use self-report about high blood pressure or diabetes without asking about the degree to which these disorders are under control with appropriate action. Indeed, because of high rates and disparate disease outcomes, it is easy to assume that all Indigenous people with these diseases do not control their disease. This is less likely to be an assumption in a dominant population subgroup. Also, health for most people means functional ability. For people whose tradition involves long distance walking or horseback riding, questions about how often one exercises does not elicit common understanding because walking or riding a horse is part of traditional daily function and is not considered "exercise". Ceremonies and traditional healing are not captured in questions that probe for social support or alternative treatments. As Waldon cites in this issue, "No single measure can give an accurate indication of the state of Maori health" [1]. Because multiple traditional dimensions define health, standard measures need qualification or improvement. He emphasizes that contemporary measures of health status require more precise definitions of Maori and of health. How identity and supporting concepts are defined give guidance for what to measure. The appropriate steps toward this goal is to include Indigenous people at all stages of the measurement process.

In Brazil, census measure for Indigenous people use definitions that match up with measurement of other ethnic groups with irregular criteria for identifying indigenous people that are not always compatible [1]. The US census also matches categories and has refined how self-identification occurs by including people within groups such as Asian/Pacific Islander or 
American Indian Alaska Native. In this case, census measurement now engages members of ethnic groups is designing questions and format. Participation in developing data collection tools is an iterative, informed process. While it may involve compromise, those qualifications and understanding about data are known ahead of time. Knowing the operational definition and how data might be qualified by circumstances of data collection is an acceptable and astute aspect of measuring identity.

In a study of 23 cooperating countries, the LancetLowitja Institute Global Collaboration for Indigenous and Tribal Health found varied methods for measuring health indicators on indigenous people [8]. Life expectancy and infant mortality rates were the most focal data, in part because these indicators are also proxy for general health and well-being. The problem of a benchmark data base, or reliable denominator, was noted as a challenge due to varied definitions and methods of data collection. In Greenland, for example, where $89 \%$ of the population are Inuit, indirect methods for deducing health data by Indigenous ethnicity were employed because Danish law that covers Greenland does not allow ethnic data collection. The Lancet-Lowitja Collaboration is a model for methodologic and cultural deliberation on ways to measure health phenomenon for Indigenous people by accounting for the actual systematic variation in data collection protocols [8].

\subsection{Invisibility}

A colonial legacy lives in data collection standards when data fail to include Indigenous people or make ineffective efforts to include Indigenous people in data sets. Common statistical methods such as oversampling are used to understand many smaller number cases but rarely are used as a logical way of data collection for indigenous people. In the US, Indigenous peoples have been called the "asterisk" nation because an asterisk (*) rather than a data point is often used in data displays $[9,11]$. Low sample sizes, low participation rates or systematic missing data are statistical issues that require thoughtful decisions about how data should be collected, interpreted, and used. Methodologic tools for small samples commonly use methods such as oversampling or pooling data over time. It matters whether this measure is employment or birth rates because calculating a percentage is different than calculating rates. Missing data are a statistical problem in many arenas that collect Indigenous data. This is the type of problem that requires negotiation. For ex- ample, when collecting national employment data, as sovereign nations, tribes may choose not to participate either because it takes so much time or the right incentives to participate have not been put in place [11].

In data analyses for Indigenous people, there can be a problem with the small denominator phenomenon that requires appropriate statistical methods to be inclusive or to appropriately study. Choosing proper data collection methods and interpreting data knowing about what the data "say" is important to make results understandable. It is also possible to significantly overstate change when rates and percent change is used. Data about California Indians find peculiar contradictions such as high rates of insurance coverage and low rates of mammography screening. Findings such as this warrant consideration about linking data sets that self-identify for different purposes (census $\mathrm{v}$ health records) and use excessive number of variables in regression analyses without considering methodologic considerations such as multi-collinearity and type 1 error [12]. Implications of the small denominator phenomenon has also been addressed in Aoteraroa-New Zealand. Indeed, a Table in this issue shows two different data results demonstrating the importance of measuring Indigenous enrollment. The Table contrasts two scenarios, one scenario that uses complete ethnic Maori criteria consistent across regions and another scenario that does not, revealing the extent of difference using Indigenous engaged definitions and ways to measure identity [1]. By establishing credible and clear criteria, meaning about measuring disparities between groups increases confidence in data for decisionmaking. Health disparities for Indigenous people are documented and replicated in well-designed studies but are more likely to be dismissed when less rigorous studies become part of a meta-analysis [12]. Therefore, it is imperative that attention be given to highest standards of data collection with informed analyses.

Astonishingly, it is possible for Indigenous people to be both over-represented and still overlooked. This is the case in situations such as in the justice system or rates of diabetes where extremely disproportionate effects are documented with sound data but neglected in action. These are circumstances when data do not activate reasonable response. Similarly, jurisdictional issues contribute to concealing significant threats as happens for missing and murdered indigenous women. (MMIW). Rather than attribute poor data on MMIW to casual concern or poor communication, attention must be given to provide mechanisms as to where and how to report and prosecute cases of missing and murdered 
women. Problems with data on this issue are rampant partly because lines of jurisdictional authority are unclear and mechanisms to count and process data are absent or vague [13]. It is interesting that the US Senate selected the word "silent" in addressing legal concern about MMIW because it illustrates the fact that data gives a "voice" for public concern. Data are essential for decision making and designing responsible systems. Data do serve as a voice to say what is important.

\subsection{Comparisons}

Data about identity vary over time [1,4-6] because definitions and participation have varied. This makes it difficult, for example, to compare US Census data on American Indians before 1960 since it was not a category marker until that time. Latin America remains uneven in including and defining Indigenous people in census data and also has different definitions over time even when measuring Indigenous people (e.g. by skin color or use of Indigenous language) [4]. Comparisons rely on the quality of instrumentation, or how something is measured. Note that statistically, measures that are reliable (consistent) are not necessarily valid (actually measuring what is purported to be measured). Reliability and validity are common terms used to say how accurate a measure is but, from a measurement point of view, they are not exactly the same.

Data involve participation in ways we often perceive as questionnaires. These are very important sources of information and often the best way to learn about a variable of interest. However, biologic data form another type of participation in data collection and measurement. Medical practice has generally been the users of biologic data. However, with the growth of commercial Direct to Consumer (DCT) analysis of DNA, biologic data to measure ethnic identity has become part of an enormous entertainment industry. Measuring DNA is reliable, that is to say results are consistent. It is valid for certain things like a disease linked to a specific gene. There is high level of confidence to establish first order relationships (siblings and parents) and less so as more inherited material increases (grandparents, great grandparents, cousins). A DNA sample is compared to a reference data base source to search for correlations in a biologic sample that contain mitochondrial DNA haplotypes (groups of DNA markers) that are similar to the reference-base. As with all correlational data results contain some margin of error. Because the data base for Europeans num- ber is in the millions, the probability for validity is better than for Indigenous people where the referencebase is dramatically smaller. Information about data bases are not easily available but all originate from self-report. Not only is the reference base of Indigenous people small in commercial Direct to Consumer (DTC) companies, some Indigenous communities and their members have refused to participate in any genetic compilation consequent to the Havasupai providing DNA samples to study a disease then discovering that the DNA samples were subsequently also used for studies on migration and other purposes not consented. This judgement became case law and also magnified the fact that exploitation persists in contemporary times perpetrated with data tools [14]. As technology and data bases mature, this technology may become more relevant. The fact that it is associated with a major source of exploitation prompted recommendations by Indigenous people from several countries to agree to guidelines on appropriate use of genomic science [14] as some tribes establish their own regulations about participating in studies using genomic tools [16].

New approaches have been created in many places and sectors where intentional action include bringing the best tools and methods to culture and context specific data for Indigenous people. This has been aided substantially by inclusion of Indigenous voices and Indigenous professionals. A government report on inquiry into mental health and addiction in New Zealand [15] documents a rationale and reorientation to examining poor results to established programs. In what is called a "people first" approach, the needs and preferences of people and communities address data sources, understanding, and response. Australia employs a three phase process to identify as aboriginal or Torres Strait Islanders: descent, self-identity and recognition by the community [6].

\subsection{Recognition and political rights}

Identification of Indigenous peoples follow parallel themes mentioned in the papers of this journal and follows a colonial legacy. As noted in Brazil, Indigenous people in much of the $20^{\text {th }}$ century were considered legally incompetent, requiring "tutela" or legal guardianship [4]. Similarly, it took nearly 200 years for US Indians to be able to vote and once suffrage occurred, the process of abridgement was required [17]. Within the matter of identity and status, tribal membership "corrections" such as among the Kanawake of Canada [18] reveal evolving methods for counting. 
Women who married outside the tribe lost their ancestral membership and the process of reconciling this elimination continues to this day. There are attempts to bridge the legal distinction between Indigenous people (defined by settler governments) and tribal members (defined by tribal governments). An alignment of legal doctrine, demographic data and tribal practice bring complex issues of identity into an arena that calls for resolution and improved, agreed upon standard definitions that allow understanding, comparison, and informed decision-making [3,19].

Considering the remarkable data experience the British brought (commercial, census, literacy, morbidity, mortality) to settler states, it is stunning to find how insufficient data were about native peoples in the lands that were colonized. Not until well into mid 20th century were Indigenous people integrated into national data systems [20]. However, the well-established data bases contain considerable relevant historic information that can be mined or inferred to understand the context of the times when specific enumeration of Indigenous people was absent or uneven.

Data are commissioned, collected and managed across many aspects of life. Data are solicited from individuals, organizations, or obtained from other sources. In current social debate is digital data obtained simply by using or holding data devices. Data about preferences in purchasing books create personal advertisements and also can be distributed, sold or hacked. Responsible people adhere to policies and standards of privacy and security to the extent they are known and knowable. This is a collective societal concern.

Among Indigenous people, data have been misused to characterize groups in stereotypical ways or with processes that exclude participation. Also, exploitation using data obtained from or about Indigenous people for external self-interest and diminishing benefit to tribes have commonly happened. Therefore, there is sound reason for suspicion among Indigenous communities about researchers who come to collect data [14].

Data sovereignty is a major concern for Indigenous people. Data sovereignty incorporates not only permission to collect data but how data can be used and, ultimately, determination about who owns data that have been collected [6]. Data sovereignty is a vital focus for the First Nations of Canada under OCAP or Ownership, Control, Access and Possession of data. The initiative, launched in 1998, upholds First Nation rights over all research that impacts them [21]. OCAP grounds its authority to own data based on treaty rights as well as the UN Declaration on the
Rights of Indigenous Peoples. Repatriation of data is a goal for OCAP and tribes in other countries. Data ownership is a concern in Brazil where divulging and sharing data with Indigenous people themselves has been a challenge [1]. Fundamental rights are violated and grievances grown when people who are involved in data measurement have decisions made using data they cannot access. The iterative and cooperative processes such as modeled in the Lancet-Lowitja Collaboration [8] suggest that matters around data sovereignty can be extended from this foundation.

Matters of Indigenous data sovereignty have been considered under tribal policy [16] and in considerable detail by interdisciplinary and intercultural Indigenous thought leaders at the "Indigenous Data Sovereignty Symposium: The Importance of Data Sovereignty for Communities" [22]. Topics included attention to fields examining approaches through the lens of law, economics, demographic, anthropology, land management, health and education. Data management and methodologic concerns must deal with quality, data linkage, access, and intersectionality. Concepts related to collection of unique data in the Indigenous sector suggest opportunities to explore culture specific determinants of resilience. Ways in which data are used and governed and processes for sharing require detailed deliberation. Indeed, the value of data ownership was reflected in a symposium session titled "Indigenous data sharing: The new land grab?".

\subsection{Land claims and identity affiliated by people of a place}

Inseparable in all definitions of Indigenous identity is their sense of place or, as more commonly constructed, land. While disputes persist about stolen versus conquered lands, the location of boundaries, and forced and coerced relocations, Indigenous identity stakes itself to a defined geographic space. Many nation states affirm land and Indigenous identity through law. Land is a particularly powerful component of Indigenous identity having shaped not only traditions associated with food, shelter, and communal organization but is highly represented in creation stories and oral traditions that guide behavior and belief. Habitation is a common correlate with racial, ethnic and cultural identity (e.g. English) though not exclusive (e.g. African Americans). As mass global migration, mixed race populations and general mobility increase, alignment with particular place or land loosen. Indigenous people are those who maintain separate ancestral identity in a place within a dominant nation-state. 
Indigenous people populate many places around the world. In the Sakha Republic in Siberia (a part of Russia that is the size of India) recent progress has been made to officially recognize Indigenous groups with legally designated regions at various internal levels (region, state, district) with native administered regional centers [23]. The Sami in Finland or Ainu of Japan are other examples of Indigenous people recognized by the nation state(s) in which they reside. The scope of their autonomy and agency varies according to rights accorded and acted on by that nation state. Circumpolar Indigenous people are among those who have nomadic histories and collectively may share ethnic and cultural ties. European Scandinavian countries and the Netherlands are among countries to use registries rather than census methodology for population statistics [7]. These registries record citizenship and place of birth. Data for purposes of health, education, and justice generally sort identification to promote better understanding of need and progress. In Sweden, ethnic self-report is not an option. Finland, for example, is reported to have the best practice for data collection that includes Indigenous Sami, however, it has been scarcely used or referred to [7]. Nevertheless, the need to know variation of ethnic health data has been led by initiatives such as the population-based study on the Sami, SAMINOR, conducted by the Arctic University of Norway.

Some milestones are worth noting. Indigenous data in the US did not count American Indian and Alaska Natives in the US Census until 1960 [5]. Also notable is a distinction for Alaska Natives who in 1971 exercised their right to self-determination after years of tirelessly lobbying the US government to take charge of their economic and political destiny and passing the Alaska Native Claims settlement Act (ANSCA). At that time, the decision by Indigenous people was to incorporate as for-profit organizations, rather than non-profit [24]. Consequently, certain benefits accrue and Indigenous people in Alaska are actual shareholders as well as members in their tribe. In addition, ANSCA established subsistence rights for Indigenous people to hunt, harvest and distribute wild animals, fish and plants according to their traditions. These rights are episodically challenged or even differentially enforced but persist exist as legal rights subject to claim. Another policy with far reaching effects on data usage and data ownership has been the European Union GDPR or General Data Protection Regulation (2015). Although this standard is enforced only by EU members, it is increasingly becoming used as a global stan- dard where liability about protecting data looms large in the context of no standard rules to assure data privacy (Jacobs, in press). Although this law and Indigenous people have not been linked in any way, the vulnerability of Indigenous people to violation of privacy is well known and the reference to current best practice is probably the most useful at this point in time.

Canada recognizes First Nation peoples and tribal rights through various legal mechanisms, with certain continuous tensions, and maintains land reserves set aside for particular First Nation peoples. In addition, another way to recognize and resolve disputes happened in 1999 when Canada created a new territory, Nunavut, by separating part of the Northwest Territories. Nunavut is inhabited primarily the Indigenous Inuit. The First Nations of Canada have many ongoing unresolved issues in tension with national and/or local authorities....

As Indigenous people whose identity is associated with place there are examples mentioned in this issue where traditions such as the place of the placenta in Maori views or American Indian tribes that bury the placenta as a symbol of belonging to the land and a particular place.

By definition land claims and affiliation with a place relates to ecology. Environmental examples such as the Standing Rock protest about building a section of oil pipeline in the US and the rapid Artic ice melt are events involving highly focused experiences that give public insight into Indigenous lives, the ownership (or disputed ownership) of Indigenous land, and how climate change singularly affects certain Indigenous communities. Oversight and regulation subject to change or challenge happen fundamentally because Indigenous people are sovereign nations with dependent nation status within nation states. Therefore, ongoing engagement in negotiation and legislative processes become essential. Such is the case in Alaska with ANSCA legislation from 1971. Since then various changing definitions, court challenges, and business encroachment shifted how ANSCA is implemented. Land management affecting subsistence rules came under partial federal control on federal lands $(60 \%$ of Alaska) as well as qualification in the state legislature where urban lawmakers outnumber rural representatives in keeping secure the rural preference.

Latin America is distinctive in many ways for Indigenous people and most particularly for identity and data. There has been systematic disregard in counting Indigenous people in distant and, in some cases, the recent past. In this issue we learn the challenges faced by 
Brazil for Indigenous people in the official statistics. Brazil had the longest period of colonization and some of the least reliable basic census measures [4]. Census data, demography that describes the whole population in a comprehensive cross section is complicated by definition, outreach, power, and limitation. Latin American countries have varied widely by nation and over time in whether or not they include Indigenous people in a census and whether and how input in measurement and interpretation engages Indigenous people.

Conflict resolution related to land claims persist In many cases land is used to define Indigeneity. If legal judgements are made then individual identity as belonging to a particular Indigenous group is required to receive claims. Early in European colonization (1840), the Treaty of Waitangi established parameters that guaranteed possession rights to the "the chiefs and tribes of New Zealand", a confederation of Indigenous people, as well as Indigenous families and individuals, conditional on a right of pre-emption by the Crown. This Treaty awarded land rights to the Maori. The Waitangi Tribunal was established in 1975 by New Zealand to hear claims regarding breaches of the Waitangi Treaty. It has reported on 1028 of more than 2500 claims. The most significant of these was settlement for Ngai Tahu land claims resulting in both land and monetary restitution for land lost in breach of the Treaty [1]. In the US, Lakota claims on treaty that gave them the Black Hills was settled for more than $\$ 100$ million in the US Supreme Court in 1980. However, the Lakota tribe, which lives in the most impoverished counties in the country, refused to receive the settlement holding that the Black hills to be sacred and not subject to settlement. With compound interest, the account in the Bureau of Indian Affairs is now worth more than billion dollars. Land and Indigenous identity are deeply entwined.

Indigenous people are characteristically people with storytelling histories. Creation and tradition stories arise from the place of Indigenous people. These stories are often written and archived, particularly as part of language revitalization projects. Another expression of identity that aligns with storytelling history, is communication of identity through art and especially through film. Movies such as Smoke Signals [25], Wind River [26], Frozen River [27] and Whale Rider [28] are fictional stories that feature contemporary Indigenous identity as central to understanding human relationships. Unique circumstances related to culture, jurisdiction, and isolation are re- vealed as profoundly universal. Film illuminates Indigenous identity with meaning and proportionality by telling stories about Indigenous life.

\section{Discussion}

There are common concerns and complications about how data are aggregated, about what assumptions are used in analyses, and matters of access, ownership and privacy. In this journal issue, we accept that common concerns are part of the conversation we should engage in together. Culture specific concerns associated with Indigenous people are vital to responsible data collection and use. Examples show how gaps lead to invisibility and misrepresentation. Improvements in data collection among Indigenous people rely on changing two critical approaches. First, is to bring to bear best practices for data methodology that would take place in any reasonable circumstance of small or hard to reach sub-groups. Secondly, the benefits of engaging Indigenous communities and Indigenous professionals provide contextual insight to guide data collection, interpretation, and application.

There have been steps made toward inclusivity in data collection for Indigenous people in larger jurisdictional data sets. Concerns about quality, measurement, and site-specific limitations continue to inform us about how to improve data collection. Papers in this issue offer guidance about how this can be done. These population-based data sets often reveal disparities and gaps in indicators of well-being consequent to marginality, minority, and vulnerable status. The history and context of people who have retained such robust Indigenous identity in the face of forces intended to exclude recognition or extinguish our identity and capacity for self-determination reveal traits of resilience. Consequently, the right to be recognized has been endorsed by the UN and by official recognition of nation states. Recognition and rights ascribed to Indigenous people vary by jurisdiction. Indigenous governance operates as communal oversight within the bounds of nation-state law where Indigenous communities reside. The sense of place that is at the heart of Indigenous identity translates into the modern world about issues of land and claims to land generally set aside in some way that recognizes Indigenous identity. While we see unevenness and continued challenge, the opportunity to gain more insight about disparities would benefit from greater inclusion of Indigenous people in measurement and leadership roles associated 
with data collection. Resolving inequities from health, education and economic disparities require serious attention to the quality of data that are collected. Conditions associated with data sovereignty require on-going mutually determined processes. Tensions related to efforts toward inclusion, data sovereignty, and data privacy are complexities that need full participation and voice from Indigenous communities. The study of resilience, particularly from within Indigenous communities, would improve measurement and instrument development that would be culturally sensitive and inform more generally about what parameters can support human flourishing for all people. For example, in considering housing data, definitions become relevant in choosing what to measure and how to measure it. Commonly, structures and number of rooms, or number of residents per number of rooms are measures used to assess quality or adequacy of housing. Those among Brazil's Indigenous people who live in their community and have a hut with a door would be prosperous while in Rio de Janeiro the house would be slum quality $[4,5]$ showing how dominant definitions distort or fail to explain the phenomenon it is intended to measure. The aims of inclusivity and equity are laudable as movement toward justice. At the same time, harmony among peoples animate a shared future with better prospects for all.

Identity as the core of human potential. People have multiple identities. Group affiliation as Indigenous transcends biology and culture since Indigenous people have maintained separateness from a dominant or conquering culture while negotiating intersections that allow a dialectic identity. In this journal issue, we posit how advances in data management often neglect addressed Indigenous people, that comparisons may be compromised because of historic absence of data, and that steps to correct these problems are feasible, important, and promising.

\subsection{Future directions}

The trajectory of serious problems comes with waves of progress, challenge, and resolution. Existing and emerging challenges arise as Indigenous people and tribes exercise more sophistication and autonomy in data collection. Measures, interpreted and used by Indigenous peoples will enrich the overall study of populations that include Indigenous subgroups and as primary sources for problem solving within group challenges. This is a dynamic process but one that increasingly calls for Indigenous people who are edu- cated and credentialed in the disciplinary fields or professional teams where such decision are made. The members of IGHIM have been served as advocates, examples, and participants in advancing best practices.

Specific identity issues related to data require negotiation and resolution. Matters associated with data sovereignty exist in principle and procedure but, similar to the land claim laws described in Alaska and New Zealand, new laws and technologies may require adjustment to figure out how to put data sovereignty into standard practice. The move to use GDPR to protect data is a new driver that needs Indigenous input. Privacy for data looms larger as more and more personal content is digital and protection standards emerge. The European Union GDPR has become a reference point as these matters become more clearly understood. What has often happened is that universal problems that affect everyone are addressed considering people who are most like the decision makers or researchers then years later after disparities or gaps appear, compensatory or adapted programs are designed. With capacities given by data technology, it makes sense to have a pluralistic plan from the beginning. Similarly, other technologies bring prospects to solve some problems with exuberance that fails to account for any downside. Particularly, as Indigenous people have their own people trained in these fields, consideration for downsides can be anticipated and confidence in collaboration can grow. Tribes such as Navajo that once prohibited participation in genomic studies consider in their own time and under their own conditions terms in which such study may be tribally approved. Recognizing Indigenous self-determination is the primary approach to resolving specific issues.

Future directions for Indigenous identity and data must presume that best practices for data management be employed, the culture and context be considered, and that we promote education and training of Indigenous youth to be participants and leaders.

\section{References}

[1] Waldon J. Identification of Indigenous People in AatearoaNew Zealand-Nga mata a taku whenua.

[2] UN Working Group 1986.

[3] Gover K. (2010) Tribal Constitutionalism: States, Tribes and the Governance of Membership Oxford University Press.

[4] Santos R. The identification of the indigenous population in Brazil's official statistics with emphasis on demographic censuses.

[5] Connolly M. (2019). 
[6] Griffiths K, Coleman C, Al-Yaman F, Cunningham J, Garvey G, Whop L, Jackson-Pulver L, Riang I, Madden R. The identification of aboriginal and Torres Strait Islander people in official statistics and other data: critical issues of international significance.

[7] Axelson P. (2018) Official statistics and Indigenous people the state of play and recent developments, $16^{\text {th }}$ Conference of IOAS 19-21 September 2018.

[8] Anderson I, Robson B, Connolly M, Al-Yaman F, Bjertness E, Kina A. (2016) Indigenous and tribal peoples' health: A population study. Lancet, April 26, 2016.

[9] National Congress of American Indians.

[10] Tidwell A, Zelln B. (2016) Introduction, Land, Indigenous Peoples and Conflict, Rutledge, New York, 1-8.

[11] Interview with United States Labor Department, November $28,2018$.

[12] Jacobs B. (2016) "California Indians" in Margaret Moss American Indian Health, Spring, 205-222.

[13] Missing and Murdered: Confronting the Silent Crisis in Indian Country, US Senate Committee on Indian Affairs, Dec $12,2018$.

[14] Jacobs B, Collmann J, Bitsoi L, Rofenbrenner J. (2010) Bridging the Divide in Genomic Sciences for Indigenous People, Journal of Law, Medicine, and Ethics, 38(3), 684-696.

[15] He Ara Oranga. (2018) Government Inquiry into mental Health and Addiction, New Zealand.

[16] Garrison N. (2018) "Genetic Ancestry Testing with Tribes: Ethics, Identity and Health Implications" Daedalus, the Journal of the American Academy of Arts and Sciences, 60-69.

[17] McCool D, Olson SM, Robinson JL. (2007) Native Vote: American Indians, the Voting Rights Act, and the Right to Vote, Cambridge University Press.

[18] Simpson A. (2014) Mohawk Interruptus: Political life across the borders of settler states.
[19] Bell C. (2004) Indigenous Dispute-Resolution Systems within Non-Indigenous Frameworks: Intercultural dispute Resolution Initiatives in Canada in Intercultural Dispute Resolution in Aboriginal Contexts, UBC Press, Vancouver, 241-279.

[20] Coleman A, Dixon S, Mare D. (2005) Maori economic development - Glimpses from statistical sources Motu Working Paper 5-15, Motu Economic and Public Policy Research September 2005.

[21] Dewar J. (2018) First Nations Data Sovereignty in Canada.

[22] University of Melbourne, Indigenous Data Sovereignty Symposium: The Importance of Sovereignty for Communities, Oct 11-12, 2017.

[23] Balzar M. (2016) Indigeneity, land, and activism in Siberia in Alan Tidwell and Barry Zellen, Land, Indigenous Peoples and Conflict, Routledge, New York, 9-27.

[24] Hensley WI. (2010) Fifty Miles From Tomorrow, Farrar, Straus \& Giroux, New York.

[25] Smoke Signals (film 1998).

[26] Wind River (film 2017).

[27] Frozen River (film 2008).

[28] Whale Rider (film 2003).

[29] Akee R. Why are Canada's First Nations Women Dying at Such an Alarming Rate, Brookings Institute blog, February $28,2018$.

[30] Gover K. (2016) Indigenous membership and human rights: When self-identification meets self-constitution, Handbook of Indigenous Peoples Rights, Routledge, New York, 35-49.

[31] Jacobs B, Ventura M. (in press) Global Faith Based Health Systems, Fondazione Remo Orseri Press.

[32] Wilson D. (2016) Satisfying Honor? The Role of the Waitangi Tribunal in Addressing land related treaty grievances in New Zealand in Alan Tidwell and Barry Zellen Land, Indigenous Peoples and Conflict, 94-107. 